\title{
Lack of perceived social support among immigrants after a disaster: comparative study
}

\author{
Annelieke N. Drogendijk, Peter G. van der Velden, Berthold P. R. Gersons and Rolf J. Kleber
}

\section{Background}

Disaster research suggests that immigrant groups who are affected by a disaster receive less emotional support than their native counterparts. However, it is unclear to what extent these differences can be attributed to post-disaster mental health problems or whether they were present before the event.

\section{Aims \\ To examine the association between lack of social support, immigration status and victim status, as well as differences in support between immigrants and Dutch natives with disaster-related post-traumatic stress disorder (PTSD). \\ Method \\ Social support and psychological distress were assessed among immigrants and Dutch natives, among affected and non-affected individuals 4 years post disaster.}

Post-traumatic stress disorder was examined in the affected groups.

\section{Results}

Affected immigrants more often lacked various kinds of perceived social support compared with affected Dutch natives. Remarkably, we found no differences in support between affected immigrants and non-affected immigrants. Immigrants with PTSD differ on only two out of six aspects of support from the Dutch natives with PTSD.

\section{Conclusions}

Results clearly indicate that differences in support between immigrants and Dutch natives are not so much a consequence of the disaster but were largely present before the disaster.

\section{Declaration of interest}

None.
Perceived social support is a term encompassing a variety of characteristics of an individual's social world and the relationship between the individual and the social environment. ${ }^{1}$ Although definitions vary, social support can be defined as those social interactions that provide individuals with actual assistance or embed them into a web of social relationships perceived to be caring and readily available in times of need. The role of perceived social support has been examined in post-traumatic responses following a myriad of traumatic events. ${ }^{2}$ With regard to the effects of disasters on the individual as well as the community, the subjective perception of social support is an influential factor in recovery. ${ }^{3}$ Studies undertaken after disasters have shown that social support has a stress-buffering effect for post-traumatic problems. ${ }^{4,5}$ Furthermore, perceived lack of social support systems and perceived lack of sharing of emotions have been found to be risk factors for post-disaster mental health disturbances. ${ }^{6-8}$

With regard to non-Western ethnic minorities, there are two rather contrasting phenomena. On the one hand, certain groups of non-Western ethnic minorities are considered to live in collectivistic communities ${ }^{9}$ and in these communities 'the self' is defined as part of a larger group such as the family. ${ }^{10,11}$ In the case of emergencies, this would imply that providing social support is more of a compelling duty than a free and voluntary act. People sacrifice their personal interests to benefit the collective, for example the extended family. ${ }^{12}$ This suggests that affected members of these communities are likely to receive more social support after disasters than affected Western natives, especially in the long term.

On the other hand, disaster research in Western countries has indicated that disaster victims who were members of ethnic minority groups received less emotional support than their affected counterparts who were members of ethnic majority groups. ${ }^{13}$ In addition, empirical studies have shown that they were indeed more at risk than Western natives of developing mental health problems (such as post-traumatic stress disorder (PTSD)) after disasters ${ }^{14,15}$ in the short, intermediate and long term. ${ }^{16}$ Interestingly, Kaniasty \& Norris ${ }^{17}$ concluded that lack of social support in the long term is a consequence of mental health problems following a disaster. As a result of more disaster-related problems faced by affected ethnic minorities, they are less likely to receive social support than affected natives.

In line with these contrasting phenomena we tested two hypotheses. The first hypothesis is: affected immigrants receive less social support than non-affected immigrants, and affected Dutch natives receive less social support than their non-affected counterparts as a consequence of the disaster and its related mental health problems. The second hypothesis is in line with the findings of Kaniasty \& Norris ${ }^{17}$ that the lack of social support is a result of mental health problems: differences in lack of social support between immigrants and Dutch natives are minimal in affected victims with PTSD. To the best of our knowledge, previous studies have not examined these two related hypotheses in one study, using an immigrant and a native comparison group. Thus, for this purpose we examined lack of perceived social support and severe mental health problems among affected and non-affected immigrants and Dutch natives and their non-affected counterparts 4 years after a major disaster. We focused on longterm experiences because it is especially during this period of time that social support may deteriorate.

\section{Method}

\section{Background}

On 13 May 2000 a devastating explosion in a fireworks storage facility occurred in a residential area in the city of Enschede in The Netherlands. As a result of the explosion, 23 people were killed, 900 were physically injured and approximately 500 homes were destroyed or severely damaged. The Dutch government 
declared it a national disaster and decided to launch the comprehensive and comparative Enschede Fireworks Disaster. The medical ethics committee of The Netherlands Organisation for Applied Scientific Research (TNO, Zeist) approved the study protocols, and all of the participants gave their written informed consent.

\section{Procedures}

The procedures, methods and non-response rates have been described in earlier studies. ${ }^{14,18,19}$ For this reason, the characteristics of the study design are only described briefly below. The study consisted of three waves of assessments: 2-3 weeks, 18 months and 4 years post disaster. In the first wave all of the adult residents (both immigrants and Dutch natives) of the disaster area were personally invited by letter to participate in the study, and several announcements were made through the local media. The study was conducted among adult residents, passers-by and rescue workers. In the second and third waves a comparison study was carried out.

Immigrants were defined as those who were foreign-born and those who were born in The Netherlands, with at least one non-native parent. In this study the immigrant group contained a large diversity of more than ten different nationalities (from Afghanistan, China, Iraq, Egypt, Eritrea, Syria, Angola, Liberia, Sierra Leone, Algeria, Bosnia Herzegovina, Iran, India, Lebanon and Mozambique), with the largest group of immigrant victims and controls in our study being people of Turkish origin (43\% in the affected group and $58 \%$ in the control group). Dutch natives were defined as those individuals who were born in The Netherlands with neither parent born outside of The Netherlands.

The comparison group were adults who had not been exposed to the disaster and who were residents of Tilburg, a town located in another part of The Netherlands with a similar historical background to Enschede. Four districts (postal areas) in Tilburg were chosen as the comparison group; residents from these districts were similar to the Enschede survivors in relation to age and gender composition, educational level, country of origin and general health status. The information was based on figures from the Dutch Public Health Status and Forecast Report. ${ }^{20}$ Within each of the districts a sample of 400 people was identified and stratified by gender, age and country of origin. They lived in a comparable residential area (i.e. comparable in relation to the composition of the population and general health status).

Both in the third wave of the main study and in the comparative study the respondents were asked to participate in exactly the same way (letter of invitation, posted questionnaire and personal telephone call). The letters were translated into English, German and Turkish (the language of the largest group of immigrants). The telephone calls were, as much as possible, made by people who could speak Dutch and a specific foreign language. For the present study, data from the third wave of the study were analysed, which was almost 4 years after the disaster (January-March 2004).

\section{Sample}

A total of 1567 disaster-affected residents completed the questionnaire in Wave 1. This is an estimated response of $30 \%$ of all of the victims in the affected neighbourhood. In Wave 3 the response rate was $69.9 \%$ for survivors who responded in both Wave 1 and Wave 3. The immigrant group had a slightly higher response in Wave 1 . The response rate of the third wave among the immigrant group was $49 \%$ of the immigrant group of the first wave.

For self-reported disaster-related experiences, the respondents and non-respondents from the first and third waves did not differ in the percentage of affected respondents who had to be relocated because of the disaster. Furthermore, both groups were equally exposed to the disaster. For psychological problems, 2-3 weeks post disaster there were no significant differences between respondents and non-respondents at the follow-up stage. Furthermore, non-response analyses of the first survey showed that the prevalence rates of mental health problems 2-3 weeks post disaster were not affected by the individuals' non-response to the survey. ${ }^{19}$

The comparison group comprised 640 non-exposed adult residents of the city of Tilburg, located in another part of The Netherlands. They lived in a comparable residential area, i.e. comparable in the composition of the population and general health status. They participated in the second wave (response $61.0 \%$ ) and the third wave (response $78.5 \%$ ).

\section{Measures}

Demographic information concerning gender, age and level of education was obtained for the questionnaire. This, including informed consent, was in Dutch, but it was also available in English, German and Turkish. The questionnaires, including the Turkish questionnaire, were translated and back translated according to the procedure of Van de Vijver \& Leung. ${ }^{21}$

\section{Psychological distress}

The 90-item Symptom Checklist (SCL-90-R) ${ }^{22,23}$ was administered to examine psychological distress. The SCL-90-R has a five-point Likert scale (from 1, 'not at all' to 5, 'extremely') and assesses symptoms over the previous 7 days. The Dutch cut-off scores for males and females of a normal population were used to identify respondents with severe psychological distress (total score). The internal consistencies were excellent $(\geqslant 0.86)$.

\section{PTSD}

The 22-item Self-Rating Scale for Post Traumatic Stress Disorder $(\text { SRS-PTSD) })^{24}$ was administered among the affected residents to assess disaster-related PTSD (based on the criteria of DSM-IV ${ }^{25}$ ) during the previous 4 weeks. Individuals with a positive score on all three subscales: intrusions (a score of at least one item from five items); avoidance reactions (a score of at least three items from seven items); and hyperarousal symptoms (a score of at least two items from five items) are considered to have a PTSD. Cronbach's alpha was excellent $(\alpha=0.95)$.

\section{Lack of perceived social support}

The 34-item Social Support List Discrepancy (SSL-D) ${ }^{26,27}$ was administered to all respondents to assess six important aspects of lack of perceived social supports: everyday emotional support, emotional support in response to problems, appreciation of support, instrumental support, social companionship and informative support. This frequently used questionnaire assesses the extent to which the received support is in accordance with the needs of the respondent. The questionnaire starts with 'What is your opinion about the extent to which people ...' followed by items such as ' . . . are affectionate towards you?', '. . . ask you to join in?', ' . . drop in for a pleasant visit?', ' . . give information about where to get things?. The items have a four-point Likert scale: 1, 'I miss it, I would like it to happen more often'; 2, 'I don't really miss it, but it would be nice if it happened a bit more often'; 3 , 'just right, I would not want it to happen more or less often'; 4, 'it happens too often, it would be nice if it happened less often'. The item scores were recorded $(1=3,2=2 ; 3,4=1)$. All of the Cronbach's alphas were excellent $(\alpha \geqslant 0.84)$. 


\section{Resources of social support}

Among the affected residents, resources of social support were examined based on the work of Rimé and colleagues, ${ }^{28}$ using two related questions: 'How many people around you can you count on in the event of problems or difficulties (not related to the fireworks disaster)?' and 'How many people around you can you count on in the event of problems or difficulties (if any) related to the fireworks disaster?. Responses were made on a seven-point Likert scale (1, 'nobody' to 7, '20 or more different people'). Our cut-off score was $>1$. People with one or more people they could count on for emotional problems were defined as having a resource for social support.

\section{Data analyses}

Chi-squared tests were conducted to assess the differences in the mental health problems experienced by the affected residents and the comparison group in demographic variables. In addition, chi-squared tests were used to examine the differences in sources of support for both groups of affected residents. All of the analyses were carried out using SPSS version 16 for Windows.

With respect to our first hypothesis, the differences in social support between the four study groups were tested by means of a one-way ANOVA. Psychological distress, gender, age and educational level were controlled by means of covariates in the one-way ANOVA. For our second hypothesis, the aforementioned analyses were repeated among both groups of disaster victims with and without disaster-related PTSD.

\section{Results}

\section{Demographic characteristics}

The four study groups (affected immigrants, affected Dutch natives, comparison immigrants and comparison Dutch natives) did not differ in gender (Table 1). The immigrants had a rather low educational level: about $60 \%$ of the victims and the comparison group had attained no more than primary or junior high school levels of education (Table 1). The differences in low educational levels were significant between the immigrant groups and the Dutch natives groups (affected group: $\chi^{2}=18.9$, d.f. $=1$,
$P<0.001$; comparison group: $\chi^{2}=9.8$, d.f. $\left.=1, P<0.01\right)$. The percentages with regard to low education level did not differ significantly between the affected and the non-affected immigrants, or between the affected and the non-affected Dutch natives. In this sample most of the respondents were married or had a permanent partner and there were no significant differences between the four study groups.

\section{Psychological distress and PTSD}

Four years post disaster the majority of the affected residents in the immigrant group (63.4\%) had severe psychological distress (Table 1). Compared with the affected Dutch native group $\left(\chi^{2}=108.8\right.$, d.f. $\left.=1, P<0.001\right)$ and the comparison immigrant group $\left(\chi^{2}=16.0\right.$, d.f. $\left.=1, P<0.001\right)$, the affected immigrant group suffered significantly more from psychological distress. The differences in psychological distress between the affected Dutch native group and the comparison Dutch native group were smaller, although significant $\left(\chi^{2}=7.6\right.$, d.f. $\left.=1, P<0.01\right)$. Furthermore, a significantly higher percentage of the affected immigrant group had PTSD compared with the affected Dutch native group $\left(\chi^{2}=105.2\right.$, d.f. $\left.=1, P<0.001\right)$.

\section{Differences in social support and aspects of perceived social support}

Approximately $30 \%$ of the affected immigrant group could not share their emotional feelings (in general or related to the disaster) with a single person (Table 1). This percentage is significantly higher than that of the affected Dutch native group (4 and $7 \%$ respectively).

Table 2 shows that when controlling for psychological distress, gender and age, the differences in lack of perceived social support between the affected immigrant group and the affected Dutch native group remained significant for all types of social support (the $F$-values range from $F=-46.2$, d.f. $=1, P<0.001$ for instrumental support to $F=17.4, \quad$ d.f. $=1, \quad P<0.001$ for informative support). Interestingly, the differences in lack of social support between the affected immigrant group and the comparison immigrant group were not significant.

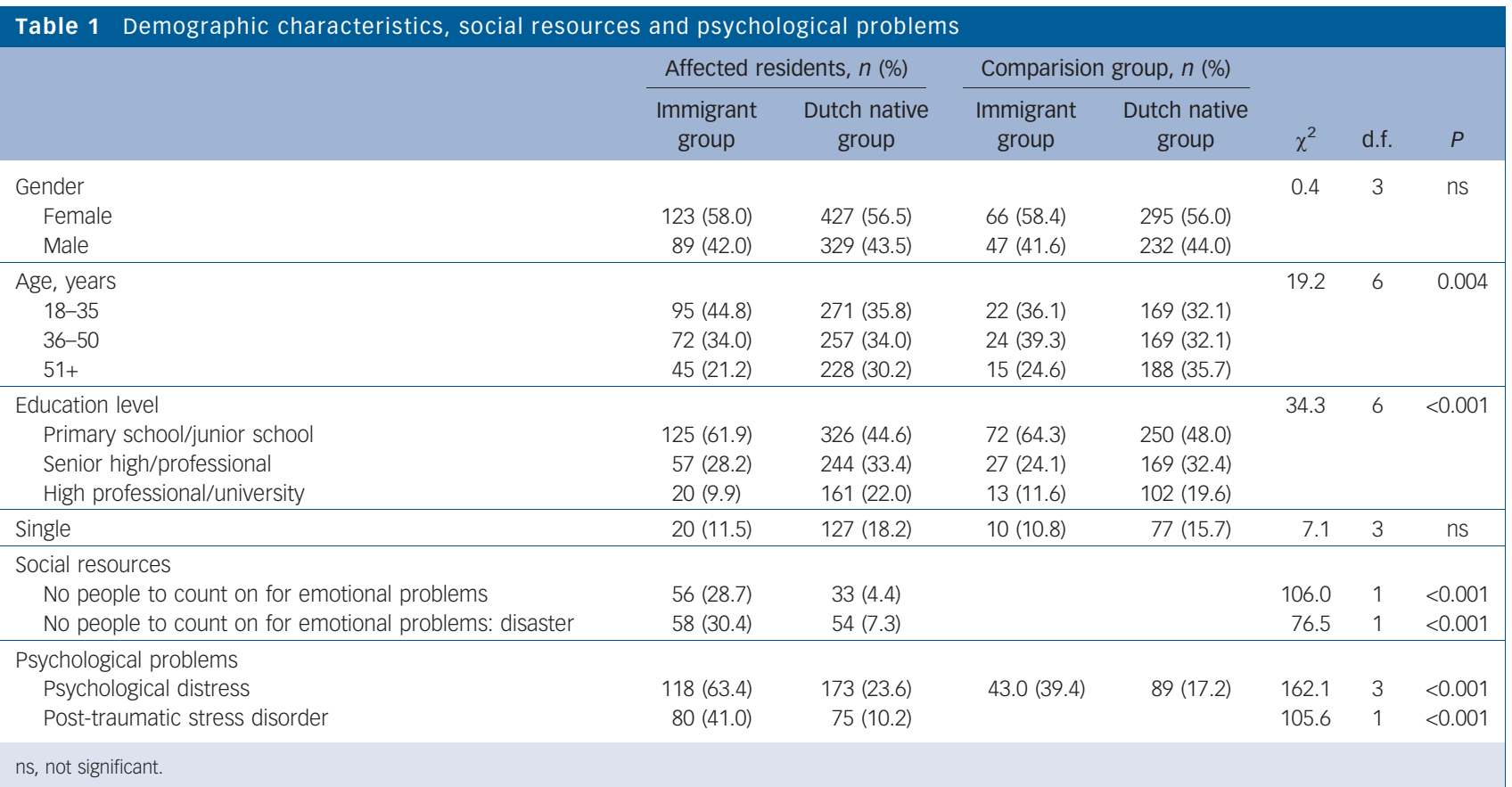




\section{Differences in perceived social support among individuals with and without PTSD}

As expected, the affected immigrant group with PTSD reported the same levels of lack of perceived everyday emotional support, emotional support with problems, esteem support and informative support as the Dutch native group with PTSD (Table $3)$. However, the levels of a lack of perceived instrumental support $(F=6.0$, d.f. $=1, \quad P<0.05)$ and informative support $(F=3.3$, d.f. $=1, P<0.05)$ were significantly different for the two affected groups. This means that the affected immigrant group felt that they would have liked to have received more instrumental support (such as a loan of money or a helping hand) and informative support (such as constructive criticism) than the affected Dutch native group.

In line with our hypotheses and the former analyses with regard to our comparison group, significant differences were found in the group of affected residents without PTSD (Table 3). Among the affected residents without PTSD, the affected immigrant group perceived less emotional support, emotional support with problems, esteem support and informative social support than the affected Dutch native group (Table 3; the $F$-values range from $F=28.1$, d.f. $=1, P<0.001$ for instrumental support to $F=5.9$, d.f. $=1, P<0.02$ for informative support).

\section{Discussion}

\section{Main findings}

This is the first comparative disaster study that has focused on the lack of perceived social support among affected immigrants and Dutch natives, as well as among non-affected residents. Were differences to be found in perceived social support 4 years after a disaster? Were these differences related to psychological symptoms or were they already present? Our results show that, in particular, the immigrant groups lacked social support in general. Our results reveal that the differences in lack of social support (often found in disaster studies) are not so much a result of the fact that immigrants experience relatively more psychosocial stress after a disaster, but originate in the lack of social support for immigrants in general.

This study confirms our first hypothesis: immigrants lacked social support more than native Dutch victims. We found that 4 years after the disaster a third of the affected immigrant group felt that they did not have one single person to talk to and they had no one with whom they could share their emotional problems. This should be considered a devastating decrease of their social support system. Among the affected Dutch native group the percentage was much lower. Furthermore, as expected, the affected immigrant group had a higher deficiency in social support than the affected Dutch native group.

This raises the question: did this lack of post-disaster social support have a long-term effect on the immigrants in particular? Remarkably, our results show that the affected and non-affected immigrant groups did not differ in deficiency of social support. This is in contrast to our first hypothesis. However, the results confirm the second hypothesis: among a group of disaster victims with comparable severe mental health problems (such as PTSD), the differences in lack of social support between the immigrant group and the Dutch native group were minimal.

\section{Possible explanations}

How can these findings be explained? After a traumatic experience such as a disaster social support is an important aspect of disaster recovery. ${ }^{8}$ Received support has been found to increase in the aftermath of a disaster ${ }^{29}$ and to be positively correlated with the severity of exposure. ${ }^{30}$ At first, just after the disaster, people look after each other, help each other to survive, and in a shattered community it is acceptable to talk about the events and the

\begin{tabular}{|c|c|c|c|c|c|c|c|}
\hline & \multicolumn{2}{|c|}{ Affected residents, mean (s.d.) } & \multicolumn{2}{|c|}{ Comparision group, mean (s.d.) } & \multirow[b]{2}{*}{$F^{\mathrm{d}}$} & \multirow[b]{2}{*}{ d.f. } & \multirow[b]{2}{*}{$P$} \\
\hline & $\begin{array}{l}\text { Immigrant } \\
\text { group }\end{array}$ & $\begin{array}{l}\text { Dutch native } \\
\text { group }\end{array}$ & $\begin{array}{l}\text { Immigrant } \\
\text { group }\end{array}$ & $\begin{array}{l}\text { Dutch native } \\
\text { group }\end{array}$ & & & \\
\hline Lack of perceived everyday emotional support & $7.35(2.61)^{\mathrm{a}}$ & $5.78(2.22)^{\mathrm{bc}}$ & $6.20(2.28)^{\mathrm{ac}}$ & $5.71(2.20)^{\mathrm{b}}$ & 5.89 & 3 & 0.001 \\
\hline Lace of perceived emtoional support with problems & $14.39(5.10)^{\mathrm{a}}$ & $11.15(3.87)^{\mathrm{bc}}$ & $12.25(4.32)^{\mathrm{ac}}$ & $10.97(3.62)^{b}$ & 7.99 & 3 & $<0.001$ \\
\hline Lack of perceived esteem support & $10.22(3.66)^{\mathrm{a}}$ & $8.08(2.57)^{\mathrm{bc}}$ & $8.51(2.76)^{\mathrm{ac}}$ & $7.81(2.46)^{\mathrm{b}}$ & 9.75 & 3 & $<0.001$ \\
\hline Lack of perceived instrumental support & $12.31(4.11)^{\mathrm{a}}$ & $9.37(2.83)^{\mathrm{b}}$ & $11.02(3.79)^{\mathrm{a}}$ & $9.05(2.53)^{b}$ & 25.71 & 3 & $<0.001$ \\
\hline Lack of perceived social companionship & $8.91(3.16)^{a}$ & $7.04(2.49)^{\mathrm{bc}}$ & $7.82(2.91)^{\mathrm{ac}}$ & $6.90(2.44)^{b}$ & 7.94 & 3 & $<0.001$ \\
\hline Lack of perceived informative support & $7.00(2.55)^{\mathrm{a}}$ & $5.59(1.90)^{\mathrm{bc}}$ & $5.93(2.06)^{\mathrm{ac}}$ & $5.39(1.79)^{b}$ & 8.29 & 3 & $<0.001$ \\
\hline
\end{tabular}

Table 3 Association between group and lack of perceived social support 4 years post disaster in disaster affected groups with or without post-traumatic stress disorder (PTSD)

\begin{tabular}{|c|c|c|c|c|c|c|c|}
\hline & \multicolumn{2}{|c|}{$\begin{array}{l}\text { Affected residents with PTSD, } \\
\text { mean (s.d.) }\end{array}$} & \multicolumn{2}{|c|}{$\begin{array}{l}\text { Affected residents without PTSD, } \\
\text { mean (s.d.) }\end{array}$} & \multirow[b]{2}{*}{$F^{d}$} & \multirow[b]{2}{*}{ d.f. } & \multirow[b]{2}{*}{$P$} \\
\hline & $\begin{array}{l}\text { Immigrant } \\
\text { group }\end{array}$ & $\begin{array}{l}\text { Dutch native } \\
\text { group }\end{array}$ & $\begin{array}{l}\text { Immigrant } \\
\text { group }\end{array}$ & $\begin{array}{l}\text { Dutch native } \\
\text { group }\end{array}$ & & & \\
\hline Lack of perceived everyday emotional support & $8.20(2.52)^{\mathrm{a}}$ & $8.08(2.82)^{\mathrm{ab}}$ & $6.81(2.51)^{b}$ & $5.52(2.00)^{c}$ & 17.16 & 3 & $<0.001$ \\
\hline Lace of perceived emtoional support with problems & $16.29(5.07)^{\mathrm{a}}$ & $15.40(5.09)^{\mathrm{ab}}$ & $13.16(4.79)^{b}$ & $10.70(3.42)^{\mathrm{c}}$ & 14.59 & 3 & $<0.001$ \\
\hline Lack of perceived esteem support & $12.04(3.86)^{\mathrm{a}}$ & $10.69(3.26)^{\mathrm{a}}$ & $9.09(3.08)^{b}$ & $7.80(2.32)^{\mathrm{c}}$ & 21.90 & 3 & $<0.001$ \\
\hline Lack of perceived instrumental support & $14.28(4.20)^{\mathrm{a}}$ & $12.40(3.67)^{\mathrm{b}}$ & $11.13(3.61)^{b}$ & $9.05(2.53)^{\mathrm{c}}$ & 29.20 & 3 & $<0.001$ \\
\hline Lack of perceived social companionship & $10.30(3.32)^{\mathrm{a}}$ & $9.14(3.03)^{\mathrm{ab}}$ & $8.11(2.78)^{b}$ & $6.81(2.33)^{\mathrm{C}}$ & 13.71 & 3 & $<0.001$ \\
\hline Lack of perceived informative support & $8.14(2.64)^{\mathrm{a}}$ & $7.10(2.37)^{b}$ & $6.27(2.23)^{b}$ & $5.42(1.77)^{C}$ & 12.87 & 3 & $<0.001$ \\
\hline
\end{tabular}


experiences. ${ }^{30}$ However, the availability and quality of social support systems can change in the long term. Often, social support declines as a function of time. The way that social support interacts with mental health problems after a disaster varies over time. ${ }^{17,31}$ In the first months after a disaster social support is a buffer for psychological stress. However, Kaniasty \& Norris ${ }^{17}$ showed that after 2 years, when (for most victims) the symptoms of distress disappeared, the victims with more psychological problems received less social support.

The results of the present study are consistent with the findings of studies by Kaniasty \& Norris. ${ }^{32,33}$ They showed that after a disaster the victims in ethnic minority groups such as Latino Americans and African Americans received less social support compared with European Americans. They concluded that these differences were because of the differential levels of mental health problems after the disaster. Kaniasty \& Norris ${ }^{17}$ suggested that a decline in social support in the long term is not uncommon in victims with higher levels of psychological stress. If individuals continue to show signs of severe psychological difficulties, this can infringe on the community spirit of successful recovery and, as a result, the attention and support from the social surroundings decline. Studies in the general Norwegian population have shown that the lack of social support, especially in non-Western ethnic minority groups, is related to a poor mental health outcome. ${ }^{34}$ However, this does not explain our finding of the lack of social support in the more healthy affected and non-affected immigrant groups.

Kaniasty \& Norris $^{33}$ raised the question: why do ethnic minorities not participate more fully in their evolving altruistic community? This study gives an answer to this question. It is likely that the lack of perceived social support was not because of the deteriorated situation of the immigrants after a disaster. In fact, the results indicate that the social support system of the immigrant group, in general, is not adequate enough, especially when compared with that of the (affected or non-affected) Dutch native groups. In other words, the lack of social support often found in disaster studies is not the result of the fact that the immigrant groups experience relatively more psychosocial stress after a disaster; the differences originate in the lack of social support in the immigrant groups in general. What can explain these ethnic differences in the groups of victims without PTSD? More collectivistic and family-focused cultures foster a focus on groups, contexts and relationships, and personal feelings, and their free expression may be relatively less important. A study by Matsumoto et $a l^{9}$ of various cultures showed that people in individualistic cultures endorse more emotional expression in interaction with members of their in-group, whereas people in collectivistic cultures endorse less.

Another important factor is the status of immigrants. Whereas the home culture of many minority groups in Western Europe is rather collectivistic and the need to look after each other is strong, the culture of a migrant may be less connected to this than the native majority. The migration has resulted in a condition distinctive from the homeland culture as well as from the new culture of the host country: the so-called condition migrante, meaning the conflict of living between two cultures, in combination with the resulting social isolation, uprootedness and low socioeconomic status. ${ }^{35,36}$ A study in Norway found that non-Western migrants had a lower level of social support compared with native Norwegians. ${ }^{37}$

Mediterranean (mainly Turkish and Moroccan) immigrants in The Netherlands tend to have a rural background with a commitment to the extended family and traditional religious practices, and had (and still have) to deal with an urban, secular and individualistic Western society ${ }^{38}$ The stresses and psychosocial problems that these people cope with every day ${ }^{39}$ can affect their social structures. A qualitative study among Turkish victims affected by the Enschede disaster ${ }^{12}$ in The Netherlands showed that especially the younger first generation (who had migrated from Turkey to The Netherlands in order to marry Turkish Dutch immigrants) might have a small social network. These (mostly) women depended (both socially and economically) on the family of their spouse. With a lack of access to Dutch society they reported that they did not have friends on whom they could rely. Furthermore, their close family lived in Turkey and, as a result of financial problems because of the disaster, they did not maintain much contact with them.

In addition, in the stricken ethnic minority community multiple households of the extended families were affected. ${ }^{12}$ It is not surprising, therefore, that there was a lack of social support after the Enschede Fireworks Disaster as there were complex practical and financial difficulties that had to be overcome. Most of the affected individuals' houses were largely destroyed. Furthermore, as a consequence of having an immigrant background, people may have had fewer individual resources (and the resources of the family may have been smaller) than the Dutch native victims. Practical problems such as the need to shelter more families caused crowded conditions to develop. Over time these stressful living conditions can result in strained family relations. ${ }^{40}$

\section{Strengths and limitations}

Strengths of our study include the large sample size, the inclusion of two non-affected comparison groups, and the use of well-validated instruments. However, some limitations should be noted. The response to this study was rather low. In the first wave (2-3 weeks post disaster) the estimated response was 30\%, with an overrepresentation of women and immigrants in comparison to the overall population affected by the disaster. Nevertheless, we found no indication that this overrepresentation affected the prevalence rates of psychosocial problems. ${ }^{19}$ However, in our analyses we controlled for severe psychological problems. This study used self-reporting questionnaires. We did not use a standardised clinical interview (such as the Composite International Diagnostic Interview ${ }^{41}$ ) to assess PTSD. Guay et al ${ }^{8}$ stated that the use of self-administered questionnaires is a limitation in most studies concerning social support. Despite the fact that the instruments used are well validated and have good psychometric properties, the social support in this study concerned the subjective perception of support. As in other studies, we have no data on provided support as perceived by significant others who have a social system similar to that of our respondents.

It is not clear whether the differences found in this study can be explained by the different cultural background of the respondents or by whether they belong to an ethnic minority. Our study has examined individuals from non-Western backgrounds who are also minority members in a Western setting. It is too complex to separate the effect of being a minority from the effect of ethnocultural factors. Furthermore, concerning the comparisons with the affected immigrants and the Dutch natives, there could be a difference in the expectation of the amount of social support they receive. It is possible that among people with a collectivistic background the level of expectation of social support is higher than that among people in the more individualistic Dutch community. The disappointment could have been amplified when the (collectivistic) community did not meet the expectations of the disaster survivors. As a consequence, the affected immigrants may have responded more negatively on this issue. However, and this is a crucial strength of this study, with the use of a non-affected comparison group we were able to counterbalance this possible influence. The results clearly suggest that 
differences in lack of social support between immigrants and Dutch natives 4 years post disaster are not so much a consequence of the disaster but were largely present before the disaster.

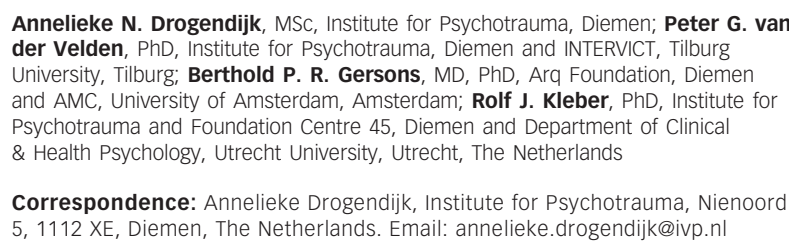

\section{Funding}

The data collection was funded by a grant from the Dutch Ministry of Public Health, Welfare and Sports. The Dutch Ministry of Public Health, Welfare and Sports had no further role in study design, in the collection, analysis and interpretation of data, in the writing of the report and in the decision to submit the paper for publication.

\section{Acknowledgements}

The Enschede Firework Disaster Study was conducted on behalf of the Dutch Ministry of Health, Welfare and Sports. We would like to thank all residents who participated in the study.

\section{References}

1 Haber MG, Cohen JL, Lucas T, Baltes BB. The relationship between selfreported received and perceived social support: a meta-analytic review. Am J Community Psychol 2007; 39: 133-44.

2 Hobfoll SE. Stress, Culture, and Community. The Psychology and Philosophy of Stress. Plenum Press, 1998.

3 Brewin CR, Holmes EA. Psychological theories of posttraumatic stress disorder. Clin Psychol Rev 2003; 23: 339-76.

4 Kaniasty K. Social support and traumatic stress. PTSD Research Quarterly 2005; 16: 1-8.

5 Chen ACC, Keith VM, Leong KJ, Airriess C, Li W, Chung KY, et al. Hurricane Katrina: prior trauma, poverty and health among Vietnamese-American survivors. Int Nurs Rev 2007; 54: 324-31.

6 Ozer EJ, Best SR, Lipsey TL, Weiss DS. Predictors of posttraumatic stress disorder and symptoms in adults: a meta-analysis. Psychol Trauma 2008; S1: 3-36.

7 Adams RE, Boscarino JA. Predictors of PTSD and delayed PTSD after disaster The impact of exposure and psychosocial resources. J Nerv Ment Dis 2006; 194: 485-93.

8 Guay S, Billette V, Marchand A. Exploring the links between posttraumatic stress disorder and social support: processes and potential research avenues. J Trauma Stress 2006; 19: 327-38.

9 Matsumoto D. Mapping expressive differences around the world. The relationship between emotional display rules and individualism versus collectivism. J Cross-Cult Psychol 2008; 39: 55-74.

10 Bhugra D. Cultural identities and cultural congruency: a new model for evaluating mental distress in immigrants. Acta Psychiatr Scand 2005; 111: 84-93.

11 Almeida J, Molnar BE, Kawachi I, Subramanian SV. Ethnicity and native status as determinants of perceived social support: testing the concept of familism. Soc Sci Med 2009; 68: 1852-8.

12 Drogendijk AN, Van der Velden PG, Boeije H, Kleber RJ, Gersons BPR. 'De ramp heeft ons leven verwoest': de psychosociale weerslag van de vuurwerkramp Enschede op Turkse getroffenen. ['The disaster ruined our lives': the psychosocial impact of the Enschede Fireworks disaster on Dutch/ Turkish victims.] Medische Antropologie 2005; 17: 217-32.

13 Norris FH, Alegria M. Promoting disaster recovery in ethnic-minority individuals and communities. In Ethnocultural Perspectives on Disasters and Trauma. Foundations, Issues and Applications (eds AJ Marsella, JL Johnson, P Watson, J Gryczynski): 15-35. Springer, 2008.

14 Dirkzwager AJE, Grievink L, Van der Velden PG, Yzermans CJ. Risk factors for psychological and physical health problems after a man-made disaster Prospective study. Br J Psychiatry 2006; 189: 144-9.

15 Norris FH, Friedman MJ, Watson PJ, Byrne CM, Diaz E, Kaniasty K. 60,000 Disater victims speak: Part I. An empirical review of the empirical literature, 1981-2001. Psychiatry 2002; 3: 207-39.
16 DiGrande L, Perrin MA, Thorpe LE, Thalji L, Murphy J, Wu D, et al. Posttraumatic stress symptoms, PTSD, and risk factors among lower Manhattan Residents 2-3 year after the September 11, 2001 terrorist attacks. J Trauma Stress 2008; 21: 264-73.

17 Kaniasty K, Norris FH. Longitudinal linkages between perceived social support and posttraumatic stress symptoms: sequential roles of social causation and social selection. J Trauma Stress 2008; 21: 274-81.

18 Van der Velden PG, Yzermans CJ, Grievink L. The Enschede Fireworks Disaster. In Mental Health and Disasters (eds Y Neria, S Galeo, FH Norris): 473-96. Cambridge University Press, 2009.

19 Grievink L, Van der Velden PG, Yzermans CJ, Roorda J, Stellato RK. The importance of estimating selection bias on prevalence estimates shortly after a disaster. Ann Epidemiol 2006; 16: 782-8.

20 Dutch Public Health Status and Forecast Report. National Atlas of Public Health. RIVM, 2001 (http://www.zorgatlas.nl/).

21 Van de Vijver FJR, Leung K. Methods and Data Analysis for Cross-Cultural Research. Sage Publications, 1997.

22 Derogatis LR. SCL-90: Administration, Scoring, and Procedure Manual I. Johns Hopkins, 1977

23 Arrindell WA, Ettema JHM. SCL-90: Handleiding bij een Multidimensionale Psychopathologie Indicator. [Manual for a Multidimensional Psychopathology Indicator]. Swets \& Zeitlinger, 1986.

24 Carlier IVE, Lamberts RD, Van Uchelen AJ, Gersons BPR. Clinical utility of a brief diagnostic test for posttraumatic stress disorder. Psychosom Med 1998; 60: 42-7.

25 American Psychiatric Association. Diagnostic and Statistical Manual of Mental Disorders (4th edn) (DSM-IV). APA, 1994.

26 Van Sonderen E. Sociale Steun Lijst - Interacties (SSL-I) en Sociale Steun Lijst - Discrepanties. Een Handleiding. [Social Support Questionnaire - Interactions (SSL-I) and Social Support Questionnaire - Deficiency (SSL-D). A manual]. Noordelijk Centrum voor Gezondheidsvraagstukken Groningen, 1993.

27 Bridges KR, Sanderman R, Van Sonderen E. An English language version of the Social Support List: preliminary reliability. Psychol Rep 2002; 90: 1055-8.

28 Rimé $B$, Finkenauer $C$, Luminet $O$, Zech $E$, Philippot $P$. Social sharing of emotion: new evidence and new questions. Europ View of Soc Psychol 1998; 9: $145-89$.

29 Norris FH, Stevens SP, Pfefferbaum B, Wyche KF, Pfefferbaum RL. Community resilience as a metaphor, theory, set of capacities, and strategy for disaster readiness. Am J Community Psychol 2008; 41: 127-50.

30 Rimé $\mathrm{B}$. The social sharing of emotion as an interface between individual and collective processes in the construction of emotional climates. J Soc Issues 2007; 63: 307-22.

31 King DW, Taft C, King LA, Hammond C, Stone EC. Directionality of the association between social support and posttraumatic stress disorder: a longitudinal investigation. J Appl Soc Psychol 2006; 36: 2980-92.

32 Kaniasty K, Norris FH. In search of altruistic community: patterns of social support mobilization following hurricane Hugo. Med J Community Psychol 1995; 23: 447-77

33 Kaniasty K, Norris FH. Help-seeking comfort and receiving social support: the role of ethnicity and context of need. Am J Community Psychol 2000; 28: 545-81.

34 Dalgard OS, Thapa SB, Hauff E, McCubbin M, Syed MR. Immigration, lack of control and psychological distress: findings from the Oslo Health Study. Scan J Psychol 2006; 47: 551-8.

35 Berry JW. Acculturation: living successfully in two cultures. Int J Intercultural Relations 2005; 29: 697-712.

36 Knipscheer JW, Kleber RJ. Help seeking behaviour of West African migrants. J Community Psychol 2008; 36: 915-28.

37 Syad HR, Dalgard OS, Dalen I, Claussen B, Hussain A, Selmer R, et al. Psychosocial factors and distress: a comparison between ethnic Norwegians and ethnic Pakistans in Oslo, Norway. BMC Public Health 2006; 6: 182.

38 Al-Issa I, Tousignant M. Ethnicity, Immigration, and Psychopathology. Plenum Press, 1997.

39 De Wit MAS, Tuinebreijer WC, Dekker J, Beekman ATF, Gorissen WHM, Schrier AC, et al. Depressive and anxiety disorders in different ethnic groups. A population based study among native Dutch, and Turkish, Moroccan and Surinam migrants in Amsterdam. Soc Psychiatry Psychiatr Epidemiol 2008; 43: $905-12$.

40 Hilfinger DAK, Lacy E. Katrina-related health concerns of Latino survivors and evacuees. J Health Care Poor Undeserved 2007; 18: 443-64.

41 World Health Organization. Composite International Diagnostic Interview (CIDI). WHO, 1993. 